\title{
Abnormal Grain Growth in Alumina: Synergistic Effects of Yttria and Silica
}

\author{
Ian MacLaren ${ }^{\dagger}$ \\ Technische Universität Darmstadt, FB Material- und Geowissenschaften, 64287 Darmstadt, Germany
}

Rowland M. Cannon*

Evans Hall (MC 1760), Lawrence Berkeley National Laboratory, Berkeley, California 94720

\author{
Mehmet A. Gülgün ${ }^{*, *}$ \\ Sabanci University, FENS, Tuzla, Istanbul 81474, Turkey
}

\begin{abstract}
Rayisa Voytovych, ${ }^{\S}$ Nicoletta Popescu-Pogrion, ${ }^{\text {II }}$ Christina Scheu, Ulrike Täffner, and
Manfred Rühle*
\end{abstract}

Max-Planck-Institut für Metallforschung, 70569 Stuttgart, Germany

\begin{abstract}
Abnormal grain growth without strong anisotropy or faceting of the grains has been observed in high-purity yttria-doped alumina specimens, often starting at the surface and spreading right through the bulk at higher sintering temperatures. This appears to occur because of an interaction between Si contamination from sintering and the yttria doping; no such effect is seen for undoped samples. Similar microstructures were observed after deliberate $\mathrm{Y} / \mathrm{Si}$ codoping. Analytical STEM showed that some grain boundaries bordering on large grains contained more Si than Y. HRTEM and diffuse dark-field imaging revealed thin $(0.5-0.9 \mathrm{~nm})$ disordered layers at some boundaries bordering large grains. It appears that $\mathrm{Si}$ impurities are accumulating at some boundaries and together with the $Y$ inducing a grain boundary structural transformation that accounts for the dramatically increased mobility of these boundaries.
\end{abstract}

\section{Introduction}

$\mathrm{D}$ URING normal grain growth, the average grain size will grow while the grain size distribution remains self-similar. During abnormal grain growth (AGG) a wide, even bimodal grain size distribution will develop and the self-similarity of the grain size distribution is lost in the process. Such an effect has been widely observed in doped or impure alumina, ${ }^{1-7}$ although it is not

S. M. Wiederhorn—contributing editor

\footnotetext{
Manuscript No. 186756. Received August 12, 2002; approved December 11, 2002 Presented at the International Symposium on Science and Technology of Alumina (Schloss-Ringberg, Germany, March 17-22, 2002)

Support for R. M. Cannon was provided in part by the Alexander von Humboldt Foundation and in part by the U.S. Department of Energy, Division of Materials Science and Engineering, under Contract No. DE-AC03-76SF00098. Support for R. Voytovych was provided by the Max Planck Society and the Alexander von Humboldt Foundation. Support for N. Popescu-Pogrion was provided by the Alexander von Humboldt Foundation.

${ }^{*}$ Member, American Ceramic Society.

${ }^{\dagger}$ Formerly at the Max-Planck-Institut für Metallforschung, 70569 Stuttgart, Germany, supported by the Alexander von Humboldt Foundation.

*Formerly at Max-Planck-Institut für Metallforschung, 70569 Stuttgart, Germany, supported by the Max Planck Society.

${ }^{\S}$ Now at LTPCM INPG, 38402 Saint-Martin-d'Heres Cedex, France.

INow at the National Institute for Materials Physics, Bucharest-Magurele, Romania.
}

observed in ultrapure alumina sintered under very clean conditions. ${ }^{8}$ Thus, AGG is an extrinsic effect in alumina induced by the presence of other cations in the ceramic.

Before the discovery of Coble, AGG was a typical occurrence during sintering of undoped (nominally pure) alumina when the density exceeded $\sim 97 \%$ and the pore sizes became too small to ensure the pinning of the grain boundaries. The discovery that doping with $\mathrm{MgO}$ prevented this and allowed sintering to full density ${ }^{9}$ spawned much discussion regarding the controlling mechanism. The most widely accepted view for many years was that solute drag from the $\mathrm{MgO}$ adsorbed at the alumina grain boundaries prevented the grain boundaries from a few grains becoming unpinned from the pores and migrating rapidly, leading to AGG accompanied by pore entrapment within the grains. ${ }^{10-13}$ This interpretation is in keeping with an extensive literature regarding the behavior in metals in which it was and still is widely considered that migration rates are extremely fast in pure materials, and that solute drag from interface active impurities can strongly impede grain growth rates, even when present in ppm levels. ${ }^{14-16}$ Experience with alkali halides, ${ }^{17,18}$ and in fluorite structured oxides, such as $\mathrm{ZrO}_{2}{ }^{19}$ is also similar. In this view, highly doped materials exhibit slow normal grain growth, and lightly doped materials are susceptible to AGG as most boundaries are pinned and a few breakaway from adsorbate clouds and move rapidly. However, there has been a persistent concern owing to the recognition that AGG in alumina is seemingly promoted in materials containing small levels of liquid forming impurities, often ones that form silicates. ${ }^{20,21}$

More recently Baik and co-workers proposed that abnormal growth was unlikely in ultrapure material, ${ }^{8}$ but was stimulated by the presence of $\mathrm{SiO}_{2}$ or $\mathrm{CaO}$ impurities, at levels less than 100 $\mathrm{ppm}$, or some equivalent concentration of each, although $\mathrm{Ca}$ is more effective per ion than is $\mathrm{Si}^{22,23}$ Subsequently, AGG in alumina has been studied in connection with doping with $\mathrm{FeO}_{\mathrm{x}}{ }^{24}$ $\mathrm{TiO}_{2},{ }^{25,26}$ or codoping with $\mathrm{TiO}_{2}$ and $\mathrm{SiO}_{2},{ }^{3,4}$ or $\mathrm{CaO}$ and $\mathrm{TiO}_{2}{ }^{5}$ One argument for the efficacy of codoping in promoting grain growth is that the two impurities could compensate regarding the need for lattice defects; this could both raise the solubility and reduce the space charge interactions that lead to impurity adsorption at the interfaces. ${ }^{26}$ Sometimes, AGG results in platelike grain morphologies with the large faces usually parallel to the (0001) plane. ${ }^{27-29}$ In some cases, a glassy film has been observed on these large facets, ${ }^{5,7,30}$ which may be related to $\mathrm{Ca}$ segregation, ${ }^{31}$ but other studies have found no evidence for such a film. ${ }^{2,32}$ In 
contrast, further doping of $\mathrm{CaO} / \mathrm{SiO}_{2}$-doped alumina with $\mathrm{MgO}$ hinders faceting and also inhibits $\mathrm{AGG}^{2,32}$

Recently, an alternative theory for AGG has been advanced, namely that under conditions in which most solid-liquid surfaces or grain boundaries are strongly faceted, the growth is limited by the sparse number of surface ledges or grain boundary dislocations to serve as attachment sites. In such a situation, a large grain should have a higher probability of forming such line defects and would tend to grow correspondingly quicker. ${ }^{2,32}$ In this theory, abnormal growth should be unlikely at temperature or impurity levels that have promoted a roughening transition. In this latter case, migration rates of all interfaces, being limited by diffusion kinetics, are less dependent on grain size. If the strong faceting in the presence of $\mathrm{Ca}$ or other impurities is held responsible for AGG, it follows that $\mathrm{MgO}$ additions prevent AGG by promoting curved grain boundaries, which are atomically rough, and by inhibiting faceting. $^{2}$

Strong anisotropy in AGG resulting in faceting occurs in many materials and has, for instance, been observed in nickel and a Ni-based superalloy, ${ }^{33,34}$ strontium titanate, ${ }^{35}$ barium titanate, ${ }^{36,37}$ and mullite ${ }^{38}$ in addition to $\mathrm{Al}_{2} \mathrm{O}_{3}$. On the other hand, there have been copious observations where AGG in ceramics (and metals) occurred without faceting or anisotropic growth. For instance $\mathrm{LiF},{ }^{17,18} \mathrm{Y}_{2} \mathrm{O}_{3}$-doped $\mathrm{Al}_{2} \mathrm{O}_{3} / \mathrm{SiC}$ nanocomposites, ${ }^{39}$ and $\mathrm{Al}_{2} \mathrm{O}_{3}$ doped $\mathrm{HfO}_{2}$ ceramics ${ }^{40}$ have all exhibited such behavior. Similarly, some alumina samples simply contaminated during sintering, ${ }^{8}$ doped with $\mathrm{Si},{ }^{6,22}$ or containing impurities ${ }^{20,41}$ have also shown AGG without strong anisotropy, or even anisotropic growth without strong faceting. ${ }^{13}$

Obviously, the mechanism of AGG in alumina, and likely in other materials in which most impurities have low solubility, is still poorly understood, despite years of study, and there may indeed be more than one important mechanism operative. Herein, we investigate the case of AGG in alumina doped with $\mathrm{Y}_{2} \mathrm{O}_{3}$ and/or $\mathrm{SiO}_{2}$ and show that abnormal growth occurs with little or no faceting or anisotropy, but strongly depends on the presence of critical levels of impurities. The evidence presented shows that migration is rapid in the presence of $\mathrm{Y}_{2} \mathrm{O}_{3}$ and $\mathrm{SiO}_{2}$ interacting together at the grain boundaries resulting in a change in the boundary core structure, the effects of which are critically discussed.

\section{Experimental Procedure}

Yttria-doped alumina ceramics were prepared as described previously ${ }^{42,43}$ from high-purity $\alpha$-alumina (AKP-3000 Sumitomo Chemical Co., Osaka, Japan) and ACS-grade high-purity $\mathrm{Y}\left(\mathrm{NO}_{3}\right)_{3} \cdot 0.6 \mathrm{H}_{2} \mathrm{O}$. The raw alumina powder had a nominal purity of $99.995 \%, \leq 20 \mathrm{ppm} \mathrm{Si}, \leq 10 \mathrm{ppm} \mathrm{Na}, \mathrm{Mg}, \mathrm{Cu}, \mathrm{Fe}$, and particle sizes of $0.3-0.7 \mu \mathrm{m}$. Several batches of material were studied; with experience they became increasingly pure. Group I materials described elsewhere had higher levels of several impurities. ${ }^{44}$ Subsequently, pressing aids were avoided in the interests of purity. The powders were ball-milled for $1 \mathrm{~h}$ in isopropyl alcohol; for group II (GII) materials $\mathrm{ZrO}_{2}$ balls were used and for all subsequent batches (GIII, GIV) high-purity (99.7\%) alumina balls were used. Milled powders were dried on a hot plate and lightly ground in an agate mortar. Samples are denoted by the $\mathrm{Y}_{2} \mathrm{O}_{3}$ content in wt ppm, e.g., Y500. In some cases, codoping with $\mathrm{Si}$ was introduced by dissolving TEOS (tetraethyl orthosilicate, $\left(\mathrm{C}_{2} \mathrm{H}_{5} \mathrm{O}\right)_{4} \mathrm{Si}$ ) in isopropyl alcohol with the aid of the chelating agent acetylacetone. The alumina was then dispersed in the TEOS-acetylacetoneisopropyl alcohol mixture, ball-milled, and dried, leading to hydrolyzation of the TEOS-chelate complex.

Green bodies were uniaxially pressed in a steel die, $13 \mathrm{~mm}$ diameter, giving specimens $\sim 8-10 \mathrm{~mm}$ thick, followed by cold isostatically pressing at $800 \mathrm{MPa}$ for $1 \mathrm{~min}$. To minimize contamination during sintering, samples were placed in a bed of alumina powder of the same composition inside a crucible, and covered with a second crucible. Sintering was done in air in a conventional furnace equipped with $\mathrm{MoSi}_{2}$ heating elements at $1450^{\circ}, 1550^{\circ}$, or $1650^{\circ} \mathrm{C}$ for various times, with the behavior before AGG described earlier. $^{42,43}$

Several different heating schedules were used. Differences can alter the tendency for a small level of relatively large, isolated pores to remain near the end of densification. ${ }^{45}$ Moreover, with more rapid heating, the material will attain higher temperatures while pores are still open and thus be more susceptible to contamination from vaporous impurities. Samples were initially cooled at about $10^{\circ} \mathrm{C} / \mathrm{min}$.

Bulk concentrations of the $\mathrm{Y}$ dopant and trace impurities such as $\mathrm{Si}, \mathrm{Ca}, \mathrm{Mg}, \mathrm{Fe}$, and $\mathrm{Zr}$ were determined using inductively coupled plasma optical emission spectroscopy (ICP-OES). The doped, milled, and dried powders were extensively analyzed and a few sintered materials were also examined. The powder was dissolved in hot phosphoric acid before analysis. For the sintered materials, slices were crushed first. The results on powders indicated that doping levels were essentially as expected and that no significant contamination of the powders occurs except for batch II materials in which 30-80 ppm of $\mathrm{Zr}$ contamination could be found. ${ }^{42}$

Microstructural analyses were conducted by cutting the specimens in half perpendicular to the sample axis, polishing the inner surface, thermally etching for various times at $1400^{\circ}$ or $1450^{\circ} \mathrm{C}$, coating with gold, and observing the microstructure using light microscopy or scanning electron microscopy (SEM). This procedure allows the easy separation of microstructural effects at the surface from those in the bulk. Mean linear intercepts, $L$, were measured from three to four SEM micrographs per sample, each containing 50-120 grains, and converted to grain sizes using the convention $G=1.5 L^{42,43}$

Specimens for transmission electron microscopy (TEM) were prepared by the conventional procedure of polishing, dimpling, and ion-beam milling. Samples were investigated by conventional TEM (Philips CM20), high-resolution TEM (HRTEM) (JEOL 3010 with Gatan Imaging Filter) and quantitative scanning TEM (STEM) with energy dispersive X-ray spectroscopy (EDXS) (VG HB501 dedicated STEM, Noran Voyager EDXS system). Amorphous phases were imaged using the diffuse dark-field imaging technique, where an image is formed from part of the diffuse diffraction ring for the amorphous material ${ }^{46-48}$ EDXS analysis in the STEM was conducted by the "box method" and quantified as described previously. ${ }^{42}$ Specimen thicknesses were estimated by quantification of low-loss electron energy loss spectra, assuming a mean free path for $100 \mathrm{kV}$ electrons in alumina of $105 \mathrm{~nm}{ }^{49,50}$ The thicknesses of the analyzed areas lay between 30 and $160 \mathrm{~nm}$, and were typically close to $100 \mathrm{~nm}$. The EDXS results were corrected for effects of beam broadening and absorption (following Alber et al. ${ }^{51}$ ).

\section{Results}

Yttria-doped $\alpha$-alumina ceramics exhibited a tendency to undergo AGG at $1550^{\circ}$ or $1650^{\circ} \mathrm{C}$, which initially seemed unexpected and unpredictable. After subsequent study, patterns emerged, which are an important aspect of the discussion that follows. Specifically, in several instances, a divergence or bifurcation in the behavior was observed between two seemingly similar sets of samples or in differing regions of the same sample. Various observations, to be elaborated, raised the suspicion that unintended contamination, most likely of $\mathrm{SiO}_{2}$, was important. Thus, a few codoped samples were also examined. The macroscopic results are described next, followed by results of chemical analysis and especially examination of the grain boundaries by TEM.

\section{(1) Microstructural Analyses of Abnormal Grain Growth in} Y-Doped Alumina

After annealing at $1550^{\circ} \mathrm{C}$ for as much as $100 \mathrm{~h}$, the rapid abnormal growth is evident mainly within a surface layer 100-200 $\mu \mathrm{m}$ deep. In these circumstances, the interior grain sizes were only a few micrometers. ${ }^{43}$ At $1650^{\circ} \mathrm{C}$, similar AGG initiated more 
quickly (within $2 \mathrm{~h}$ ) at the surface, giving similar microstructures, but had a tendency to penetrate quickly into the bulk of the specimens (many $2 \mathrm{~h}$ specimens already had some AGG in the bulk). This AGG depends strongly on composition as illustrated in Table I, showing that samples with no yttria or with sufficiently high yttria did not exhibit pronounced abnormal growth, whereas those with 150-1000 ppm yttria were especially sensitive.

The effect of composition on AGG is nicely shown in Fig. 1(a). This is a bilayer specimen, half of which was pressed from Y0 (i.e., pure undoped) powder, and half from Y1000, GIII powder, and then sintered at $1550^{\circ} \mathrm{C}$ for $12 \mathrm{~h}$. Very strong AGG is found near the surface, but only on the Y1000 side. On the Y0 side, the grain size near the surface is smaller than in the bulk. The bulk microstructure is similar for both sides of the bilayer, having equiaxed grains with an average size of $G \approx 5 \mu \mathrm{m}$ and less than $1 \%$ pores (see Ref. 43 ).

In addition, Fig. 1(b) shows an SEM micrograph from a section taken parallel to the surface for a sample of Y500, GII material, also sintered at $1550^{\circ} \mathrm{C} / 12 \mathrm{~h}$. Here it can be seen that the equiaxed grains exhibit little evidence of faceting and have many sizes ranging from 50 to $150 \mu \mathrm{m}$; there are relatively few small grains $(<20 \mu \mathrm{m})$ remaining in the microstructure. Examination of similar regions after $6 \mathrm{~h}$ showed a highly bimodal grain size distribution, with large grains similar to those in Fig. 1(b) growing into a matrix of grains with $G \approx 3 \mu \mathrm{m}$. Thus, Fig. 1(b) presents a microstructure that had experienced a wave of abnormal growth with the fast moving grains having mostly impinged, yielding a size distribution which may be tending back toward normal.

Figure 2 represents an evaluation of the mean linear intercept of the interior regions against annealing time at $1650^{\circ} \mathrm{C}$ for various samples. First note that for many samples heated directly to $1650^{\circ} \mathrm{C}$, after attaining a grain size of $\sim 6 \mu \mathrm{m}$ the growth was normal, nearly independent of Y doping, and exhibited decaying growth kinetics, i.e., the growth rate exponent was much higher than for parabolic growth $(n \sim 6 \gg 2)$. However, after $12 \mathrm{~h}$ the interior of the Y300 sample exhibited AGG with a bimodal microstructure, whereas no AGG was noted for Y0 and Y3000 samples even at this time.

Two batches of Y150, GIV material, presintered at lower temperature exhibited striking differences during annealing at $1650^{\circ} \mathrm{C}$. For the GIVp samples having the higher porosity $(\approx 2.4 \%)$ after initial sintering at $1550^{\circ} \mathrm{C}$, the grain growth exhibited persistently wide, bimodal size distributions with rates that accelerated up to at least $10 \mathrm{~h}$, reaching grain sizes in excess of 500 $\mu \mathrm{m}$. Sizes for the small and large grained areas are delineated in Fig. 2. For Y150 samples where a special heating schedule was used to promote maximum densification (porosity $<0.5 \%$ ) before annealing at $1650^{\circ} \mathrm{C}$, GIVd, no AGG was observed up to $10 \mathrm{~h}$. These samples again exhibited stagnating grain growth in which the size distributions remained narrow, and the growth rates and sizes converged with the data for other samples with rates decreasing more rapidly than for parabolic growth.

Finally, Fig. 3(a) shows a light micrograph from the interior of a full sized sample doped with $500 \mathrm{wt}$ ppm yttria, sintered for $96 \mathrm{~h}$ at $1450^{\circ} \mathrm{C}$ to a high density $(98.9 \%)$ and then annealed at $1650^{\circ} \mathrm{C}$ for $12 \mathrm{~h}$ (reaching $99.5 \%$ dense). This yielded a microstructure with regions of relatively small grains about $5-10 \mu \mathrm{m}$ in size coexisting with many large grains about $50-200 \mu \mathrm{m}$ in size. This microstructure is similar to that shown in Fig. 3(b) of a Y150 GIVp sample sintered at $1550^{\circ} \mathrm{C}$ for $2.5 \mathrm{~h}$ and then at $1650^{\circ} \mathrm{C}$ for $5.5 \mathrm{~h}$. It should be noted that the grain morphology in both samples is

Table I. Dependence of Abnormal Grain Growth on $\mathrm{Y}_{2} \mathrm{O}_{3}$ Content and Sintering Temperature

\begin{tabular}{|c|c|c|c|c|c|c|}
\hline \multirow{2}{*}{$\begin{array}{l}\text { Sintering } \\
\text { temperature } \\
\left({ }^{\circ} \mathrm{C}\right)\end{array}$} & \multirow[b]{2}{*}{ Where? } & \multicolumn{5}{|c|}{ Composition $\left(w t \% \mathrm{Y}_{2} \mathrm{O}_{3}\right)^{\dagger}$} \\
\hline & & Y0 Y150 & Y300 Y500 & Y1000 & Y1500 & Y3000 \\
\hline 1550 & Surface layer & $0+$ & ++++ & ++ & + & 0 \\
\hline 1650 & Surface and bulk & $0++$ & ++++ & ++ & - & 0 \\
\hline
\end{tabular}

${ }^{\dagger} 0$ indicates no AGG, + indicates some AGG, and ++ indicates widespread AGG.
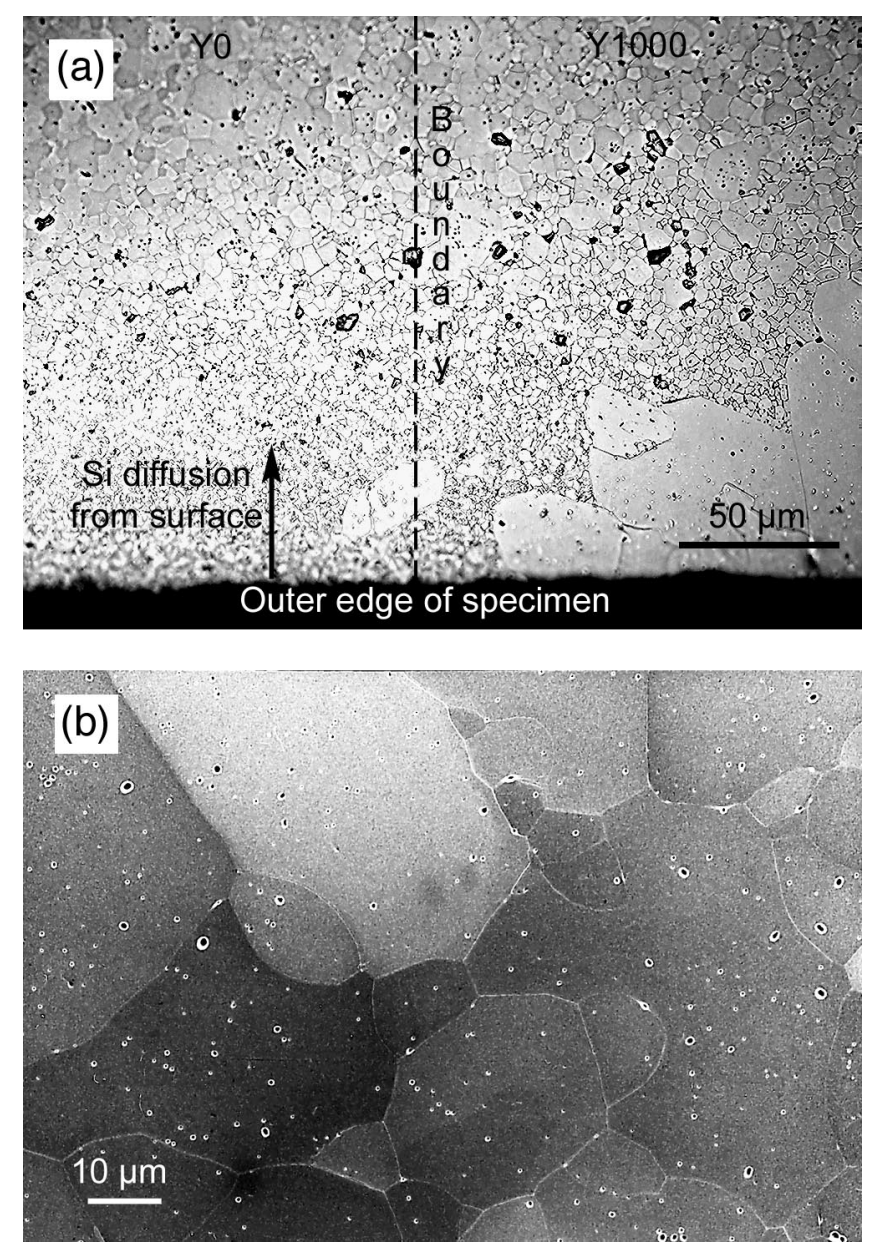

Fig. 1. (a) Light micrograph of the surface region of a sandwich specimen half from undoped alumina (left) and half doped with $1000 \mathrm{wt}$ ppm $\mathrm{Y}_{2} \mathrm{O}_{3}$ (right); note that AGG appears at the surface only on the Y-doped side. (b) SEM micrograph of the microstructure in the surface region of a GII, Y500 specimen, sintered at $1550^{\circ} \mathrm{C} / 12 \mathrm{~h}$.

fairly random; i.e., grains are nominally equiaxed even if boundaries are irregular in shape, there are many curved boundaries, and there is little obvious faceting or shape anisotropy.

\section{(2) Abnormal Grain Growth with $\mathrm{Y}_{2} \mathrm{O}_{3} / \mathrm{SiO}_{2}$ Codoping}

As it was suspected that $\mathrm{Si}$ diffusing in from the surfaces plays a key role in initiating AGG in Y-doped samples, some experiments with deliberate $\mathrm{SiO}_{2}$ doping or codoping were conducted. Samples containing $300 \mathrm{wt}$ ppm $\mathrm{Y}_{2} \mathrm{O}_{3}$ and $150 \mathrm{wt}$ ppm $\mathrm{SiO}_{2}$, as well as just 150 wt ppm $\mathrm{SiO}_{2}$ and no $\mathrm{Y}_{2} \mathrm{O}_{3}$ were prepared. The codoped concentration results in a cation concentration of $\mathrm{Si}$ about equal to that of $\mathrm{Y}$ in the ceramic.

Microstructural analysis of a sample codoped with Si and Y and sintered at $1550^{\circ} \mathrm{C}$ for $4 \mathrm{~h}$ revealed AGG as shown in Fig. 4(a) with some grains reaching sizes of up to $50 \mu \mathrm{m}$, whereas the majority of grains are still smaller than $5 \mu \mathrm{m}$. Sintering at $1650^{\circ} \mathrm{C}$ for $1 \mathrm{~h}$ caused extensive AGG with many grains larger than $50 \mu \mathrm{m}$ in diameter, as shown in Fig. 4(b). The microstructures are similar to those produced by the effect of contamination on yttria-doped alumina in that the grains have fairly equiaxed shapes, although somewhat more indication of faceting or anisotropy is evident with the codoping. Samples doped just with $\mathrm{SiO}_{2}$ (no $\mathrm{Y}_{2} \mathrm{O}_{3}$ ) exhibited normal grain growth at these same sintering conditions. This result affirms that AGG is promoted by a combination of $\mathrm{SiO}_{2}$ and $\mathrm{Y}_{2} \mathrm{O}_{3}$, and that either dopant alone has a much weaker or no effect. 


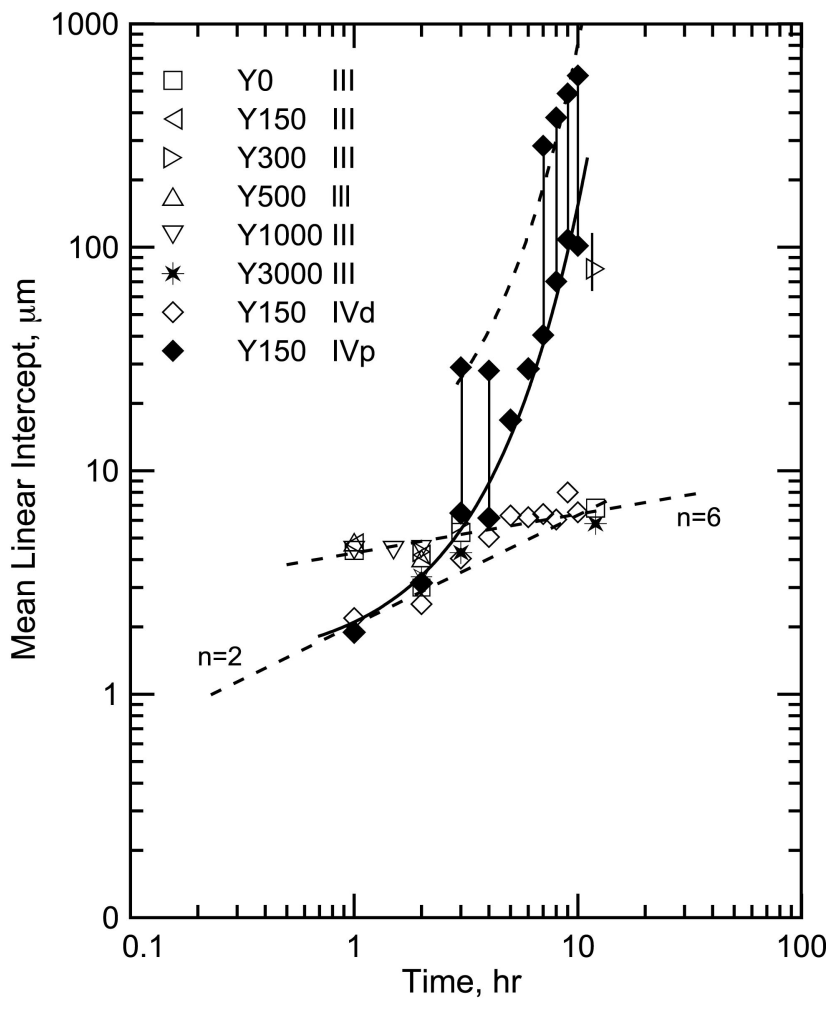

Fig. 2. Graph of approximate grain size range (expressed as the mean linear intercept) versus annealing time at $1650^{\circ} \mathrm{C}$ for a variety of different samples.

\section{(3) Studies of Grain Boundary Chemistry and Structure in AGG Samples}

To cause AGG, the $\mathrm{Y}$ and $\mathrm{Si}$ ions must be affecting some grain boundaries such that their mobility at $1550^{\circ}$ or $1650^{\circ} \mathrm{C}$ is significantly enhanced. Chemical analysis using ICP-OES of the sample surface regions that exhibited AGG has been unable to find any notable concentrations of other metal impurities not present in the bulk; typically both surface and bulk regions had $30 \pm 10 \mathrm{wt}$ ppm $\mathrm{Fe}, 15 \pm 5$ wt ppm $\mathrm{Ca}$, and $10 \pm 3$ wt ppm $\mathrm{Mg}$. The $\mathrm{Si}$ is rather more difficult to detect by ICP-OES. With such quantities of material as were available using only the surface layer of a sample, Si was not found but the detection limit was fairly poor at $\sim 100$ wt ppm.

To identify mechanisms, it is desirable to investigate in detail the chemistry and structure of grain boundaries in samples which display AGG, and in particular those that are bordering between the fine grains being consumed and some of the very largest grains. However, this can be difficult once the grains exceed $50 \mu \mathrm{m}$ owing to cracking from the thermal expansion anisotropy induced stresses.

The grain boundary chemistry, characterized in terms of the Gibbsian excesses, was determined at many grain boundaries by EDXS analysis conducted in a dedicated STEM. There is high segregation of $\mathrm{Si}$ to boundaries between abnormally grown, but impinged grains in the surface layer of a Y500, GII sample sintered at $1550^{\circ} \mathrm{C}$ for $12 \mathrm{~h}$ (shown in Fig. 1(b)) compared with levels in the small grains from the interior, as listed in Table II. In this case, $\Gamma_{\mathrm{Si}}$ was $8.3 \pm 5.2$ cat. $/ \mathrm{nm}^{2}$, and was highly variable from one boundary to another or even one area to another on the same boundary in the outer region. Between small grains, $\Gamma_{\mathrm{Si}}$ was mostly below 1 cat. $/ \mathrm{nm}^{2}$ (i.e., below the limit for reliable detection). The GII samples had been contaminated by $\mathrm{Zr}$, but as shown previously, the adsorption statistics behave approximately as though the $\mathrm{Y}$ and $\mathrm{Zr}$ compete for the same sites; ${ }^{42}$ the sum $\Gamma_{\mathrm{Y}}+$ $\Gamma_{\mathrm{Zr}}$ was essentially the same in the outer and inner regions, i.e., 7.3 and $7.5 \mathrm{cat} . / \mathrm{nm}^{2}$, respectively. For comparison, the average planar
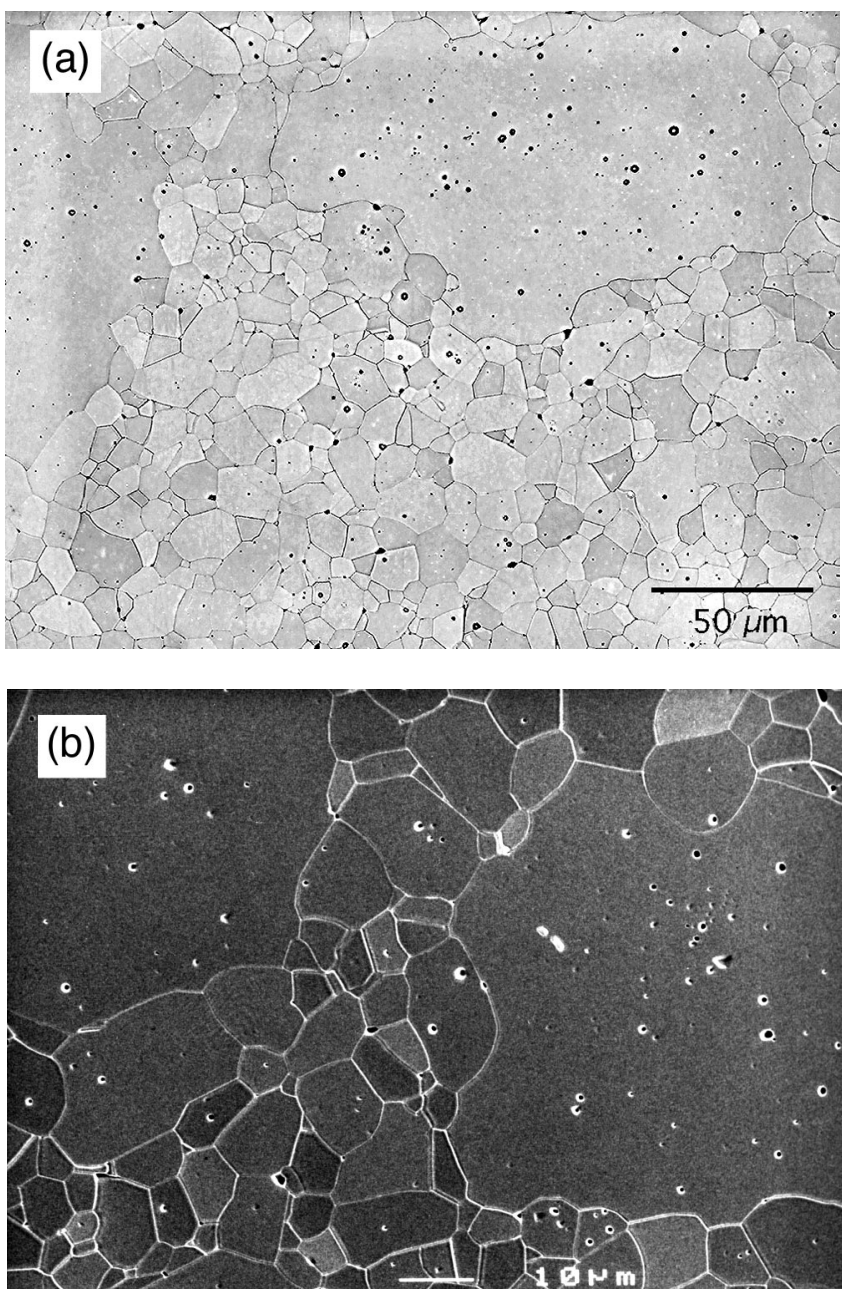

Fig. 3. Bulk AGG in alumina ceramics: (a) light micrograph of a sample doped with $500 \mathrm{wt}$ ppm $\mathrm{Y}_{2} \mathrm{O}_{3}$ and sintered at $1450^{\circ} \mathrm{C}$ for $96 \mathrm{~h}$ and then at $1650^{\circ} \mathrm{C}$ for $12 \mathrm{~h}$; (b) SEM image of a sample doped with 150 wt ppm $\mathrm{Y}_{2} \mathrm{O}_{3}$, sintered at $1550^{\circ} \mathrm{C}$ for $2.5 \mathrm{~h}$ and $1650^{\circ} \mathrm{C}$ for $5.5 \mathrm{~h}$.

density of $\mathrm{Al}$ ion sites, and thus the planar density of sites for 1 monolayer coverage, is 13 cat. $/ \mathrm{nm}^{2}$.

From EDXS analysis of 10 different grain boundaries in the Y500 GIII sample annealed at $1650^{\circ} \mathrm{C} / 12 \mathrm{~h}$ shown in Fig. 3(a), a number of different classes of boundaries could be identified. These are listed in Table III with the grain boundary excess concentrations of Si and Y. First, some grain boundaries (class 1) between relatively small grains were analyzed, at which some Y, 4.7 cat. $/ \mathrm{nm}^{2}$, and no Si could be detected above the detection limit for the conditions of about $1 \mathrm{cat} . / \mathrm{nm}^{2}$. Second, three boundaries were found (class 2), which showed less Y and low but clearly

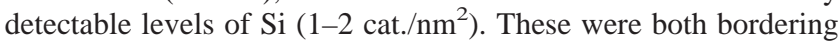
on at least one larger grain $(>20 \mu \mathrm{m})$. Finally two grains were found having relatively high levels of $\mathrm{Si}$, together with even lower levels of Y (class 3: GB3.1 and GB3.2). These were both boundaries at the edge of extremely large grains $(50-100 \mu \mathrm{m})$, which appeared to be bordering smaller grains. A STEM high angle annular dark-field image of one of these boundaries (GB3.1) is shown in Fig. 5. It is interesting that the Si content, exhibiting peak values of $\Gamma_{\mathrm{Si}}$ up to $14 \mathrm{cat} . / \mathrm{nm}^{2}$, changes sharply from one side of the crack (GB3.1) to the other (GB2.3), the crack being along a third grain boundary which cracked and etched away during ion-beam thinning. This, together with the difference between the Si contents for GB2.2 areas 1 and 2, emphasizes that the $\mathrm{Si}$ is very inhomogeneously distributed along the boundaries, as is the Y. For essentially all of these boundaries, the Ca levels were well below the detection limit, $\ll 1$ cat. $/ \mathrm{nm}^{2}$. The levels of boundary adsorbates found here were less than those in the prior 

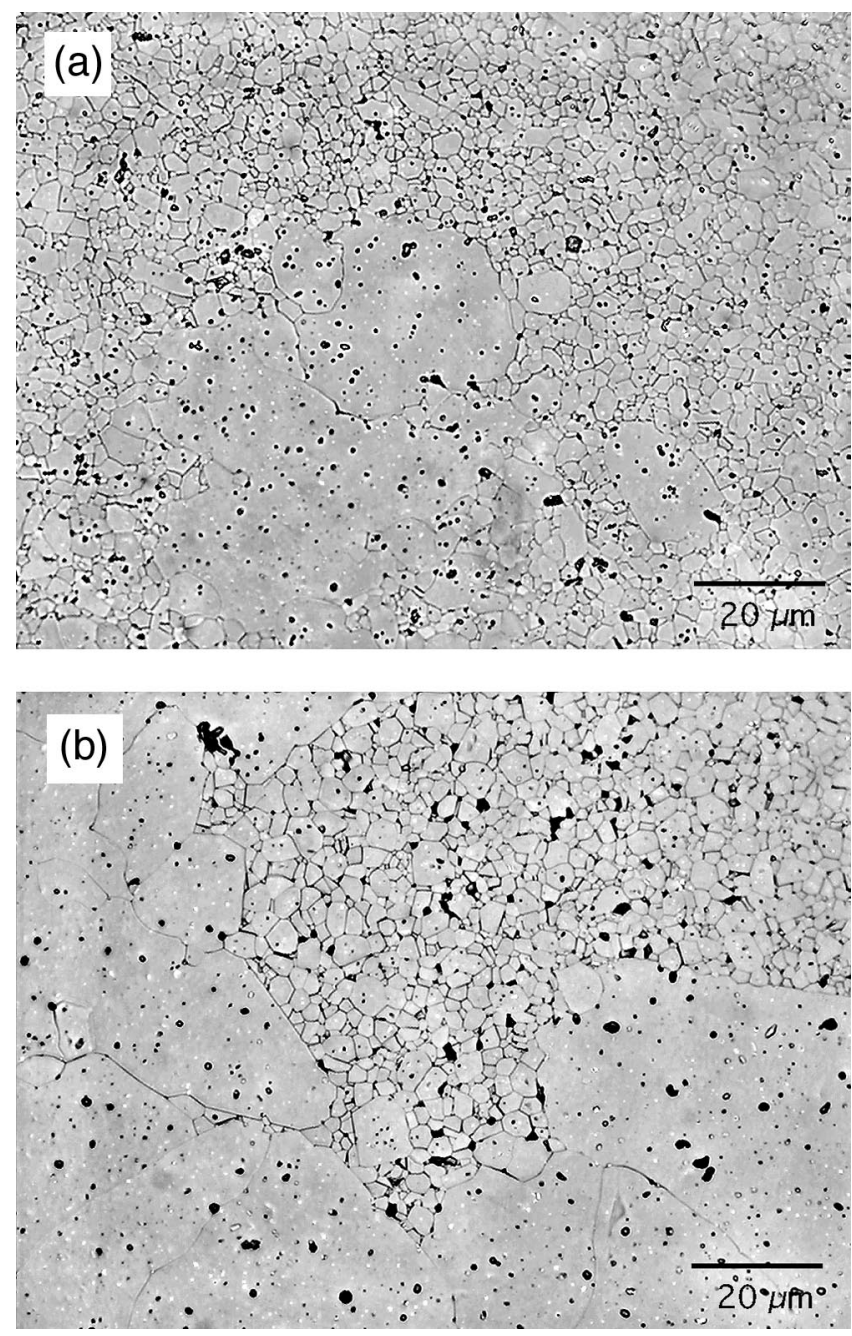

Fig. 4. Light micrographs of samples codoped with $\mathrm{Y}$ and $\mathrm{Si}$ : (a) sintered at $1550^{\circ} \mathrm{C}$ for $4 \mathrm{~h}$; (b) sintered at $1650^{\circ} \mathrm{C}$ for $1 \mathrm{~h}$.

sample (Table II). However, the annealing temperature was higher (which mildly reduces the level of $\Gamma_{\mathrm{Y}}$ found in equilibrium with yttrium aluminate garnet $\left.(\mathrm{YAG})^{42}\right)$, and this sample experienced AGG with the least, if any, external $\mathrm{SiO}_{2}$ contamination.

Figure 6 shows a diffuse dark-field image of a grain boundary between an extremely large grain (of the order of $100 \mu \mathrm{m}$ across) and another large grain, which was at least $40 \mu \mathrm{m}$ across. A thin bright line (about $2 \mathrm{~nm}$ wide) is readily visible at the grain boundary, indicating the presence of an amorphous region at the grain boundary core. ${ }^{46-48}$ It has previously been shown that measurements of amorphous film thickness from diffuse dark-field images typically give values 50\%-100\% larger than those made by HRTEM, ${ }^{52}$ and can in no way be regarded as a reliable measurement. Thus all that can be said from this is that the amorphous film is significantly thinner than $2 \mathrm{~nm}$. It should be noted that other grain boundaries bordering on large grains also show a similar contrast in diffuse dark-field images, with a similar thickness of the bright line. Little or no such diffuse contrast could be detected for grain boundaries between small grains. Also, pockets of amorphous material at grain boundary triple junctions were never observed in this sample.

HRTEM was used to confirm the presence of amorphous material at grain boundaries. Figure 7(a) is an HRTEM image of the grain boundary shown in Fig. 6. There is an extremely thin disordered layer at this grain boundary, which was estimated from this image to be about $0.5 \mathrm{~nm}$ thick. To show the disordered layer more clearly, Fourier-filtering was used to remove the contribution of crystalline material to the image as described elsewhere. ${ }^{53}$ The resulting filtered image, displayed in Fig. 7(b) shows the amorphous layer very clearly. The apparent width of the disordered layer is slightly wider in this image, about $0.9 \mathrm{~nm}$. This method will tend to overestimate the thickness if the grain boundary is not perfectly edge-on, and measurement from the raw HREM image will tend to underestimate the thickness in this case. However, it is equally true if the disordered region is wavy within the thickness of the foil, or even rough on a near atomic scale, the Fourier filtered image would show the wider extent of disorder, and the unfiltered image the greater extent of ordered material. For this reason, it is believed that the true average film thickness lies between the two extremes, probably close to $0.7 \mathrm{~nm}$.

It should be noted that in this and another similar image from another grain boundary, the boundaries were not parallel to any low index plane in either of the two crystals separated by them. Moreover, although the boundaries were fairly straight, they were not faceted, nor were they atomically flat; rather a small degree of waviness was noted in the direction in the specimen plane, and can be expected in the direction parallel to the electron beam. A grain boundary having a similar but less disordered structure with a thin disordered core has also been observed between abnormal grains in the surface layer of a Y500 GII sample, sintered at $1550^{\circ} \mathrm{C}$ for $12 \mathrm{~h}$.

\section{Discussion}

AGG results when boundaries surrounding a small fraction of the grains can move at far higher velocities than those for the rest of the grains. The key question is why? In some way or other, grain boundaries at the edge of the large grains are "special," although perhaps not in the crystallographic sense of possessing a particular orientation relationship. Thus, it is important to understand what is special about the fast moving boundaries.

A common perception about such behavior has been that most of the boundaries were pinned either by second-phase pores or particles or by adsorbed solute, and that at critical levels of the pinning entity a few boundaries are able to break away and move rapidly through the matrix of small grains. ${ }^{15,17,18,54,55}$ A central issue is that the rapidly moving boundary must be able to persistently resist being arrested as it repeatedly encounters pores and adsorbate clouds while consuming matrix grain boundaries. ${ }^{18}$ One proposed solution to this entails boundaries that are resistant to solute attachment owing to special crystallography. ${ }^{14} \mathrm{~A}$ fundamentally different criterion, which circumvents these concerns with avoiding reattachment, has been suggested recently., ${ }^{2,32}$ In this conception, the boundaries are essentially all faceted with motion being limited by a paucity of steps, ledges, or boundary dislocations to serve as sites for atom attachment or detachment. Then, a large grain has a statistical advantage in terms of having or generating such sites, and can grow abnormally; under this mechanism, the abnormal growth is suppressed once the material is heated above a roughening/defaceting transition temperature..$^{2,32}$ The fact that the microstructures observed in this study show little faceting or anisotropy, especially for the fast moving boundaries, means that such an AGG mechanism based on ledge-limited growth $^{2}$ as has been proposed for $(\mathrm{Ca}, \mathrm{Si})$-doped alumina ${ }^{32}$ can be discounted, as can any other mechanism relying on crystallographic anisotropy.

\section{(1) Sources of Silica}

In the Y-doped alumina studied herein, it is clear that $\mathrm{SiO}_{2}$, either introduced as an impurity during sintering, deliberately added as a dopant, or even present in the powder works with the $\mathrm{Y}_{2} \mathrm{O}_{3}$ to promote AGG.

Although strenuous efforts were made to eliminate impurities in the production of these samples, it is possible that some contamination could have come onto the sample surfaces during pressing or sintering. In particular, it is likely that $\mathrm{Si}$ was evaporated from the $\mathrm{MoSi}_{2}$ heating elements in the furnace in the form of $\mathrm{SiO}$ (via the reaction $\left.2 \mathrm{SiO}_{2} \Leftrightarrow 2 \mathrm{SiO}_{v}+(2-v) \mathrm{O}_{2}\right)$. This can then condense as $\mathrm{SiO}_{2}$ onto the sample surfaces and into the near-surface region 
Table II. STEM EDXS Analysis of Grain Boundary Excesses of Various Ions in Y500, GII, Sintered at $1550^{\circ} \mathrm{C}$ for $12 \mathrm{~h}$

\begin{tabular}{lllll}
\hline \multicolumn{1}{c}{ Sample region } & $\mathrm{Y}\left(\right.$ cat. $\left./ \mathrm{nm}^{2}\right)$ & $\mathrm{Zr}\left(\right.$ cat. $\left./ \mathrm{nm}^{2}\right)$ & $\mathrm{Si}\left(\right.$ cat. $\left./ \mathrm{nm}^{2}\right)$ & $\mathrm{Ca}\left(\mathrm{cat} . / \mathrm{nm}^{2}\right)$ \\
\hline Outer layer (33) & $5.2 \pm 1.5$ & $2.1 \pm 1.5$ & $8.3 \pm 5.3$ & $\approx 1.5 \pm 1.5^{\ddagger}$ \\
Inner region (23) & $4.0 \pm 1.5$ & $3.5 \pm 1.9$ & $<\mathrm{mdl}(\sim 1.0)^{\S}$ & $<\mathrm{mdl}^{\S}$ \\
\hline
\end{tabular}

${ }^{\dagger}$ Values in parentheses are the number of spectra. ${ }^{\dagger}$ Includes many zero readings and some readings $>5 \mathrm{cat} . / \mathrm{nm}^{2}$. Errors quoted are statistical standard deviations, and include no estimate of systematic errors. ${ }^{8} \mathrm{mdl}=$ minimum detectability limit.

through open porosity. Such a process would be ever more pronounced for higher furnace temperatures. Transport of $\mathrm{SiO}_{2}$ through the vapor phase in this manner has previously been demonstrated by Simpson and Carter. ${ }^{29}$ It has also been discussed by Bae and Baik, ${ }^{8}$ who have demonstrated contamination of ultrapure alumina during sintering, resulting in abnormal growth. In this case, the contamination was believed to be $\mathrm{SiO}_{2}$ from the $99.8 \%$ pure alumina crucibles. Sone and co-workers ${ }^{7}$ have observed the formation of surface layers showing AGG on alumina as a result of Si contamination during pressing, and detected $\mathrm{Si}$ at some boundaries; calcia contamination was also suspected because of the platelike grain morphologies.

In the present case, it seems that these impurities are first diffusing into the ceramic through open porosity, obviously affecting the surface more than the bulk. It should be pointed out that AGG occurs only with low to moderate Y levels, indicating that $\mathrm{Si}$ impurities and the $\mathrm{Y}$ work together to promote abnormal growth. The longer times needed to initiate AGG inside samples sintered to very high density before heating to $1650^{\circ} \mathrm{C}$ may be caused by the closure of all porosity. This would hinder transport of Si impurities into the bulk of the ceramic. The AGG in the interiors of the full-sized samples, especially the one presintered at $1450^{\circ} \mathrm{C}$ (Fig. 2(a)), may essentially reflect the effects of only the $\mathrm{Si}$ initially present in the powder itself $(<30 \mathrm{ppm} \mathrm{Si})$.

\section{(2) Abnormal Growth Mechanism}

Silica alone can induce AGG in alumina, but only at rather higher temperatures or higher doping levels. ${ }^{6,22,41}$ It is noted that $\mathrm{Ca}$ can also promote abnormal growth and that arbitrary combinations of $\mathrm{Si}$ and $\mathrm{Ca}$ can be comparably effective. ${ }^{6,22}$ The present situation differs. There is evidently a range of $\mathrm{Y}+\mathrm{Si}$ contents in which AGG is strongly promoted, whereas no evidence exists that $\mathrm{Y}$ alone promotes abnormal growth, and the required levels of $\mathrm{Si}$ alone reported to cause $\mathrm{AGG}^{41}$ are far higher when normalized per unit area of boundary than those measured here.

In the case of the present materials, analytical STEM showed that some grain boundaries, which are seemingly the fast moving ones, had become enriched in Si while still containing some Y. Dark-field TEM and HRTEM investigation showed that some such boundaries possess amorphous or disordered cores, with thicknesses measured by HRTEM clearly less than $1 \mathrm{~nm}$. It appears likely that this boundary disorder is related to the presence of both
$\mathrm{Si}$ and $\mathrm{Y}$ at the boundaries. It is, of course, well known that $\mathrm{SiO}_{2}$-rich boundary films can occur in $\mathrm{Al}_{2} \mathrm{O}_{3}$ compositions containing silica and other dopants/impurities, usually with thicknesses exceeding $1 \mathrm{~nm}$ and usually existing in the presence of pockets of liquid (which may be crystallized or glassy after cooling). ${ }^{5,7,30,44,56}$ The disordered layers shown in the present work are, however, much thinner $(\sim 0.7 \mathrm{~nm})$ than those observed previously and furthermore are not associated with the presence of amorphous pockets at triple junctions. These are, therefore, distinctly different from either the films or liquid pockets observed in more highly doped or less pure alumina. They could reasonably represent an early stage in the transition from crystalline grain boundaries containing some segregant atoms to those in a material having several atomic layers of amorphous material at most boundaries, and excess liquid phase (glassy material) at multiple grain junctions, as the impurity level (chemical activity) is raised.

It would therefore seem plausible to suggest that this structural change of the grain boundary core to a thin disordered layer as a result of $\mathrm{Si}+\mathrm{Y}$ enrichment is the reason that some boundaries have a much higher mobility than the average, resulting in the abnormally fast growth of some grains in the ceramic. These disordered boundaries must display property changes at $1550^{\circ}$ or $1650^{\circ} \mathrm{C}$ that favor a high mobility.

In this context, it is important to ask why the normally growing grains are moving so slowly and how the boundary core transformation disables this. This is not obvious and will be the topic of future papers. However, several classes of explanation merit comment. Clearly particle drag from YAG cannot be the cause, as this effect is not very strong even at the highest doping levels used where YAG is just present at levels of about 0.25 vol\%. Moreover, grain growth is also extremely slow without any Y present, ${ }^{43}$ and so the rates cannot reflect solute drag from the $\mathrm{Y}$ despite its strong tendency to segregate. ${ }^{42,57}$ An important class of argument is that all of the boundaries are impeded by solute drag from other impurities in the material; such effects are well known for metals where small levels of unintended impurities can have more effect than the deliberate dopants having higher solubility and added at higher levels. In this instance, some insights can be established as there is analytical TEM data that shows that most impurities, other than Y, are present at the grain boundaries before AGG only at area concentrations of less than $1 \mathrm{~nm}^{-2}$ (i.e., they were not detected in analytical TEM), whereas the Y can be present at much

Table III. STEM EDXS Analysis of Different Classes of Boundaries in the Y500, GIII Material Sintered at $1450^{\circ} \mathrm{C}$ for $96 \mathrm{~h}$ and $1650^{\circ} \mathrm{C}$ for $12 \mathrm{~h}^{\dagger}$

\begin{tabular}{|c|c|c|c|c|c|}
\hline Boundary class & Boundary & $\begin{array}{l}\text { Number } \\
\text { of analyses }\end{array}$ & Type & $\Gamma_{\mathrm{Si}}\left(\right.$ cat. $\left./ \mathrm{nm}^{2}\right)$ & $\Gamma_{\mathrm{Y}}\left(\right.$ cat.nm $\left.{ }^{2}\right)$ \\
\hline (1) Normal GBs & GB1.1-1.6 & 12 & Small-small & $<\mathrm{mdl}$ & $4.7 \pm 1.5$ \\
\hline (2) Low Si GBs & $\begin{array}{l}\text { GB2 } 1 \\
\text { GB2 } 2.2 \text { area } 1 \\
\text { GB2 } 2.2 \text { area } 2 \\
\text { GB2.3 }\end{array}$ & $\begin{array}{l}6 \\
3 \\
3 \\
6\end{array}$ & $\begin{array}{l}\text { Small-medium } \\
? \\
? \\
\text { Big-big }\end{array}$ & $\begin{array}{l}1.8 \pm 1.4 \\
1.3 \pm 0.4 \\
<\operatorname{mdl} \\
1.6 \pm 1.5\end{array}$ & $\begin{array}{l}2.4 \pm 1.1 \\
3.5 \pm 0.6 \\
3.5 \pm 0.6 \\
2.6 \pm 1.5\end{array}$ \\
\hline (3) High Si GBs & $\begin{array}{l}\text { GB3.1 area } 1 \\
\text { GB3.1 area } 2 \\
\text { GB3.2 }\end{array}$ & $\begin{array}{l}6 \\
3 \\
4\end{array}$ & $\begin{array}{l}\text { Big-small } \\
\text { Big-small } \\
\text { Big-small }\end{array}$ & $\begin{array}{r}10.3 \pm 3.6 \\
2.6 \pm 0.2 \\
3.7 \pm 2.2\end{array}$ & $\begin{array}{l}\quad 2.1 \pm 1.4 \\
<1 \\
3 \text { areas }<\mathrm{mdl} \text {, } \\
1 \text { area } 3.1\end{array}$ \\
\hline
\end{tabular}

The mdl is the minimum detectability limit and is usually $1-2$ cat. $/ \mathrm{nm}^{2}$, depending on the total number of counts in the spectrum, the scan width, and other experimental parameters. Errors quoted are statistical standard deviations, and include no estimate of systematic errors. 


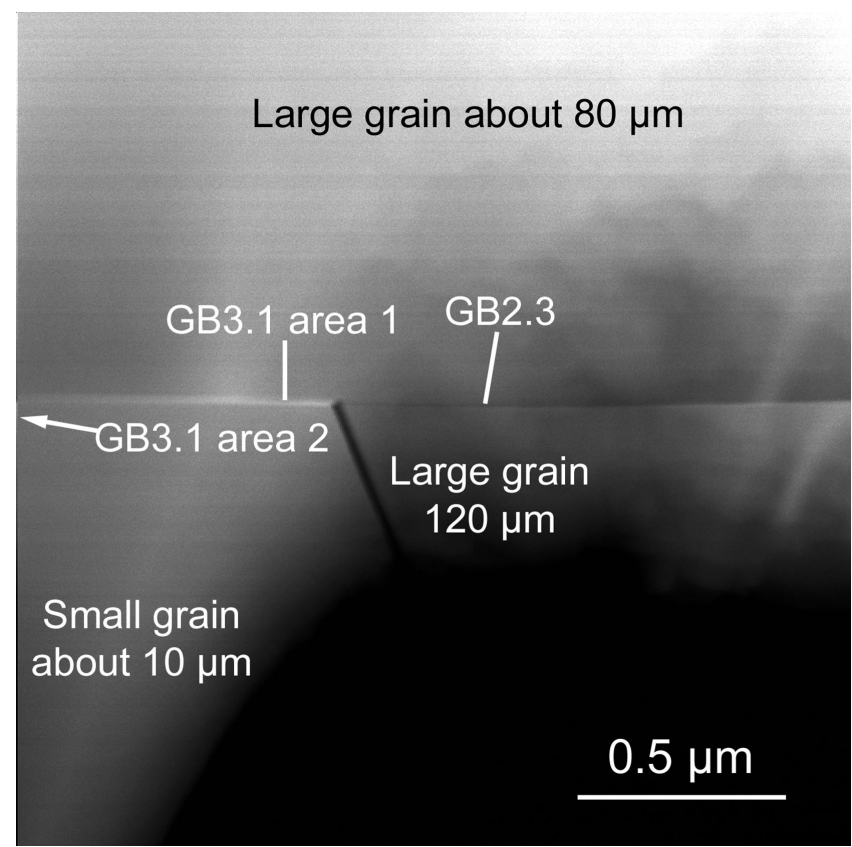

Fig. 5. STEM HAADF image of an area where 3 grains meet in a GIII, Y500 material sintered at $1450^{\circ} \mathrm{C} / 96 \mathrm{~h}$ and $1650^{\circ} \mathrm{C} / 12 \mathrm{~h}$; EDXS analyses of different boundary areas are given in Table III.

higher levels. ${ }^{42}$ Finally, it may be that as the small grains grow, the inherent mobility in alumina is simply far smaller than estimates that are based on independent diffusion like jumps across the core of a disordered boundary, for example, the Turnbull relation ${ }^{58}$ or refined versions thereof. ${ }^{16,59}$ The mobilities that describe the normal grain growth observed here are several orders of magnitude less than such an estimate for the intrinsic mobility, given in Ref.

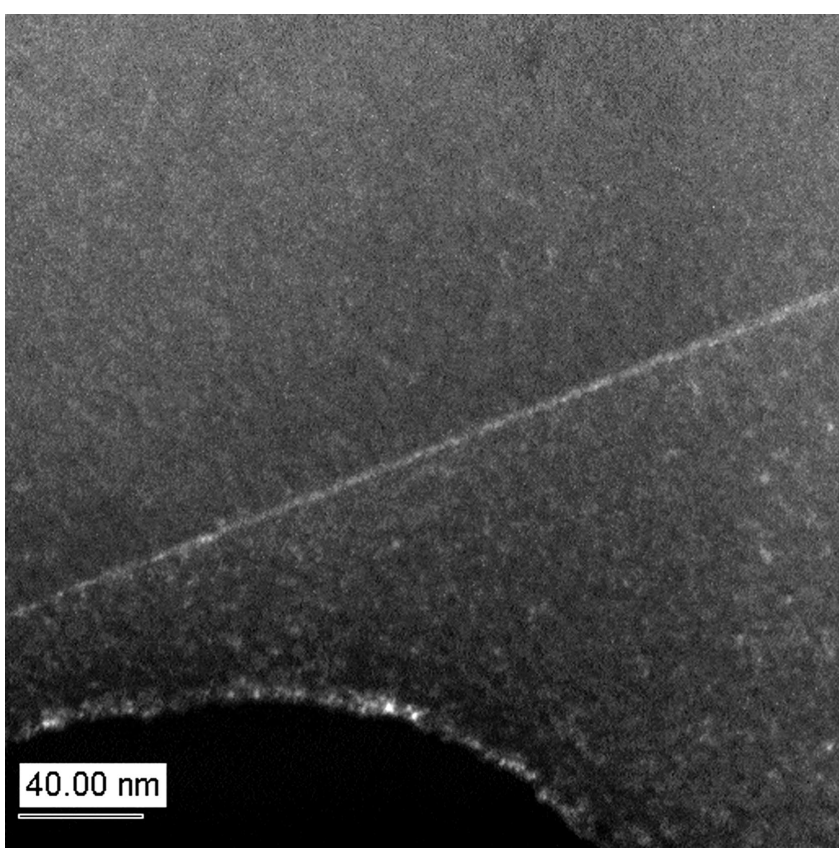

Fig. 6. Diffuse dark-field image of a grain boundary at the edge of a large grain in the material sintered at $1450^{\circ} \mathrm{C}$ for $96 \mathrm{~h}$ and $1650^{\circ} \mathrm{C}$ for $12 \mathrm{~h}$ showing that some amorphous material is present at the grain boundary.

17. The cause for this could be related to the existence of more highly coherent regions, possibly involving micro- or nanofacets, than are commonly considered to exist, or may be a general feature of ionic materials in comparison with metals. In either event, if the boundary core becomes substantially disordered, migration could occur without being limited by inadequate attachment sites or impeded by well-bonded, atomically coherent patches. However,
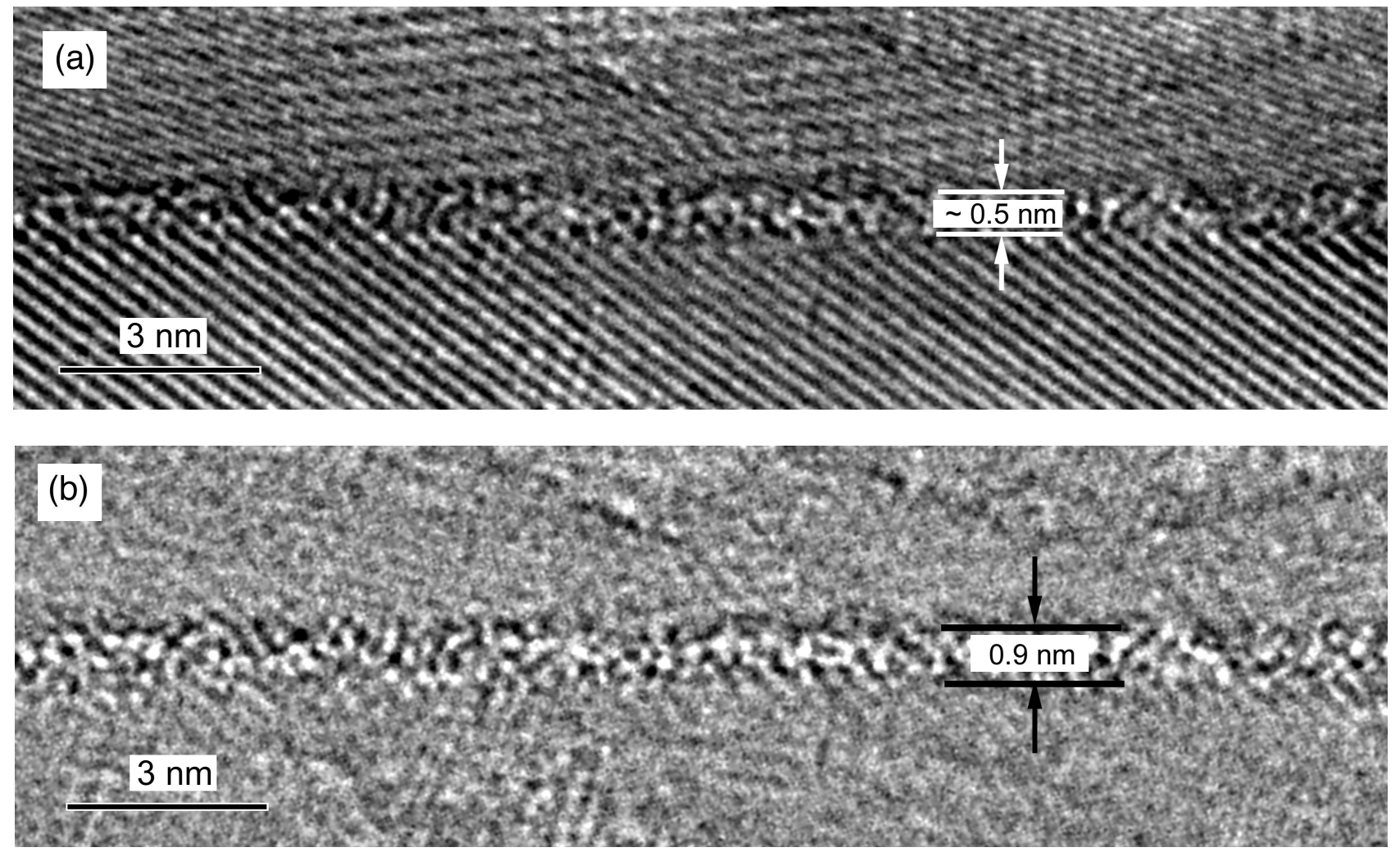

Fig. 7. HRTEM images of grain boundaries having disordered/amorphous cores: (a) grain boundary between two large grains; (b) image (a) after Fourier filtering to remove crystalline contributions to the image, thus enabling the clearer observation of the amorphous core. 
increased core disorder could also diminish the attractive forces for solute segregation, and thereby diminish solute drag.

Previously it was shown that $\mathrm{Y}$ enriches at the boundaries as small grains grow, during which period most of the yttria in the system is adsorbed at the grain boundaries; this trend continues, until the adsorption reaches a peak at a level that is high enough to induce nucleation of YAG. ${ }^{42}$ Then, the $\Gamma_{\mathrm{Y}}$ falls toward a level dictated by the activity of $\mathrm{Y}$ in equilibrium with the presence of YAG as a second phase. Similar behavior may be expected with $\mathrm{SiO}_{2}$ impurity which is clearly interface active and has a low solubility in the lattice, although the saturation value for segregation will probably correspond to several monolayers of Si. Thus, it is of interest to determine the grain boundary compositions associated with AGG.

It may also be relevant to note that a eutectic exists between $\mathrm{Al}_{2} \mathrm{O}_{3}, \mathrm{Y}_{2} \mathrm{O}_{3}$ and $\mathrm{SiO}_{2}$ at $1371 \pm 5^{\circ} \mathrm{C}^{60}$ and a eutectic point composition (in $\mathrm{mol} \%$ ) of $33 \% \mathrm{AlO}_{3 / 2}, 18 \% \mathrm{YO}_{3 / 2}, 49 \% \mathrm{SiO}_{2}{ }^{61}$ Moreover, liquid at this eutectic composition ${ }^{60}$ and indeed from a whole region in this portion of the phase diagram can be quenched from the melt into a glassy state. ${ }^{62}$ In comparison to this, the eutectics for the pure $\mathrm{SiO}_{2}-\mathrm{Al}_{2} \mathrm{O}_{3}$ system occur at $1595^{\circ} \mathrm{C}(\mathrm{Si}-$ rich) and $1840^{\circ} \mathrm{C}$ (Al-rich). It should, of course, be noted that the phase diagrams referred to here are determined for bulk systems, and behavior surely differs in the dimensionally constrained environment of a grain boundary. Nonetheless, this shows that amorphous structures of Al-Y-Si oxides are relatively stable and may be one reason that the grain boundary mobility is so much higher in the presence of $\mathrm{Y}_{2} \mathrm{O}_{3}$ and $\mathrm{SiO}_{2}$ than in the case of just $\mathrm{SiO}_{2}$ doping. Also, the ternary mixture may have a higher diffusivity than would be expected with $\mathrm{a} \mathrm{SiO}_{2}$-rich region.

AGG is, of course, an inhomogeneous effect, and in this case, is probably strongly influenced by the $\mathrm{Y}_{2} \mathrm{O}_{3}$ distribution in the green body and the $\mathrm{SiO}_{2}$ distribution, as impurity or diffusing in from the surface. Those grains that receive a little extra Si may then grow more quickly. As a grain continues to grow, it will receive further $\mathrm{Y}$ and $\mathrm{Si}$ from the annihilation of the grain boundaries being consumed. The lower the Si content present, then the more grain growth that will be necessary before the $\mathrm{Si}$ at the boundary rises to the critical level. It is of interest to identify those critical segregation levels. Another question is then, what becomes of this excess $\mathrm{Y}$ and $\mathrm{Si}$ as growth continues?

Examination of Table III shows that there is a marked difference in the composition of grain boundaries in the fine-grained matrix material being consumed and that being carried by the rapidly moving boundaries, i.e., those between large and small grains. The concentrations at boundaries in fine-grained regions being consumed may be near to, and so indicate, the critical levels needed to actually induce the AGG. A comparison of the boundary compositions in Tables II and III also indicates that the range of compositions critical for possible initiation or those being carried may involve higher excesses of $\mathrm{Si}$ and $\mathrm{Y}$ at $1550^{\circ} \mathrm{C}$ than at $1650^{\circ} \mathrm{C}$. However, the data are consistent with the levels of $\Gamma_{\mathrm{Y}}$ $\left(+\Gamma_{\mathrm{Zr}}\right)$ needed to trigger AGG being approximately that for equilibrium with YAG (which is a little lower at $1650^{\circ}$ than $1550^{\circ} \mathrm{C}$, as shown in Ref. 42) and so locally may be in the supersaturation regime. Evidently, achieving this level per se is helpful but not sufficient to trigger AGG, or it would have been readily observed in the samples with high levels of Y, e.g., Y3000. The presence of some adsorbed $\mathrm{Si}$ is also needed at the boundary to trigger the disorder transition that permits rapid migration. Based on the data from Table II, from the interior of a sample minimally contaminated enough to cause AGG, it appears that this level of $\mathrm{Si}$ can be much less than that of Y. However, as the boundary accelerates, it loses a considerable amount of the Y needed to initiate AGG, and enriches in $\mathrm{Si}$ which continues to be swept up by the migrating boundary.

Here it may be fruitful to make a comparison with the solute drag breakaway grain growth theory. In this case, AGG occurs when some boundaries break away from a cloud of pinning impurities and then move with near intrinsic mobilities, while the majority of boundaries are still impeded by segregated impurities. ${ }^{63-65}$ Then, the fastest moving boundaries are also the "cleanest," i.e., having the least impurities or segregants. This mechanism implies that solute is left behind in the bulk of the large grains after each breakaway event, possibly in the form of ghost boundaries. (This may be difficult in $\alpha$-alumina, since most cations have extremely low solubilities in bulk alumina, which would require distributing them over a wide region.)

Meanwhile, in the proposed new model, carrying a certain content of $\mathrm{Y}$ and $\mathrm{Si}$ at the boundary is essential to allow the high mobility for AGG; however, it would also be a disadvantage to accumulate these ions at the boundary ad infinitum, as the amorphous film would become thicker and thicker. This is not necessarily good for boundary mobility, for instance, owing to larger diffusion distances. Indeed, thicker $(>1 \mathrm{~nm})$ grain boundary films have been observed between the grains in small-grained regions remaining in some samples after experiencing $\mathrm{AGG}^{66,67}$ and in Si-doped samples which did not show AGG. ${ }^{4}$ Thus, some Y and $\mathrm{Si}$ must be lost from the grain boundary to maintain high mobility, and this is most easily accomplished by precipitation, which must be entrapped within the growing grain to avoid excessive drag. Excess $\mathrm{Y}$ can be simply precipitated as $\mathrm{YAG}^{42}$ which is normally seen both on grain boundaries and enclosed within the larger grains in abnormally grown samples. Si could, in principle, be concurrently precipitated into a third phase, but it can also be incorporated either into the YAG particles or onto their surfaces, as has been demonstrated recently. ${ }^{44}$ This would result in a microstructure where many YAG precipitates are found within the large grains, as is normally observed in these materials. However, it should be emphasized that for samples examined here in detail, the Si content has not yet reached the solubility limit, as no glassy pockets (or silicate particles) are seen; the preponderance of the $\mathrm{Si}$ is still in the grain boundary adsorption layer and the $\mathrm{Si}$ excess at the boundaries may be much less than expected when the chemical activity is high enough to make an additional phase, i.e., bulk silicate liquid, that would fix the activity. Nonetheless, the wide Si distributions seen at the rapidly moving boundaries (Table II) may reveal the start of a process of developing macroscopic liquid regions.

Thus, a general feature of the behavior being contemplated is that with surface-active, low-solubility impurities present, as normal grain growth occurs, the grain boundaries sweep up impurity-as shown previously. ${ }^{42}$ Then, a critical level of impurity is reached that can trigger a transformation whose function is to make the boundary more mobile than are the rest. The condition to sustain AGG depends on maintaining an appropriate range of impurity at the boundary as it is being swept up and does not rely on the crystallography of the fast moving grain boundary.

One remaining question concerns the reason that no AGG is observed for higher $\mathrm{Y}_{2} \mathrm{O}_{3}$ doping levels, especially $3000 \mathrm{wt}$ ppm $\mathrm{Y}_{2} \mathrm{O}_{3}$. It seems most likely that this is a result of the other effect that occurs at high doping levels, namely that as soon as a reasonable sintered density has been achieved, the grain boundary $\mathrm{Y}$ level is high enough to induce the immediate precipitation of YAG. ${ }^{42}$ In fact, widespread YAG precipitation has been observed by TEM in a Y3000 sample sintered for just $5 \mathrm{~min}$ at $1650^{\circ} \mathrm{C}$. This then fixes the grain boundary $\mathrm{Y}$ concentration to a specific value in equilibrium with the YAG particles. Having closely spaced YAG particles should then help to prevent the compositional inhomogeneities which may be important in starting AGG. Perhaps equally important, however, since Si coprecipitates into/onto YAG particles, ${ }^{44}$ then widespread YAG precipitation would also reduce the Si level at the grain boundaries, which would of course suppress AGG.

\section{Conclusions}

AGG is readily observed in high-purity yttria-doped alumina samples sintered in a furnace with $\mathrm{MoSi}_{2}$ heating elements, but not for undoped or highly $\mathrm{Y}_{2} \mathrm{O}_{3}$-doped samples. This phenomenon initially occurs at the sample surface, promoted by $\mathrm{SiO}_{2}$ impurity, 
but it can penetrate through or even initiate within the bulk for longer sintering times, especially at higher temperatures. Abnormal growth typically started in material with grain sizes less than $10 \mu \mathrm{m}$, which was experiencing stagnating normal grain growth, and often yielded grains of $50-150 \mu \mathrm{m}$ in size. In exceptional cases, involving low doping and annealing at $1650^{\circ} \mathrm{C}$, grains could grow as large as $500 \mu \mathrm{m}$. These abnormal grains do not show strong anisotropy or faceting, and have rather random morphologies, with a prevalence of curved grain boundaries. Similar AGG morphologies were obtained for samples deliberately codoped with $\mathrm{Y}_{2} \mathrm{O}_{3}$ and $\mathrm{SiO}_{2}$ when sintered at $1550^{\circ}$ or $1650^{\circ} \mathrm{C}$.

TEM studies showed $\mathrm{Si}$ as well as $\mathrm{Y}$ at the grain boundaries, both in the surface region of a specimen sintered at $1550^{\circ} \mathrm{C}$ for $12 \mathrm{~h}$, and in the bulk of a specimen sintered at $1450^{\circ} \mathrm{C}$ for $96 \mathrm{~h}$ plus $1650^{\circ} \mathrm{C}$ for $12 \mathrm{~h}$. The interaction of $\mathrm{Y}$ and $\mathrm{Si}$ segregants is associated with the formation of a thin (0.5-0.9) nm disordered layer at the grain boundaries, which could be imaged with HRTEM, and also gave a signal using conventional diffuse dark-field imaging in TEM.

It is believed that the incorporation of both $\mathrm{Si}$ and $\mathrm{Y}$ into the boundaries causes the formation of these very thin disordered regions, which in turn play a key role in increasing the mobility of the boundaries at $1550^{\circ}$ or $1650^{\circ} \mathrm{C}$, thereby yielding fast growth rates for some grains and an abnormal grain size distribution. The AGG is triggered when the combined adsorption level is near a monolayer, and leads to extensive grain growth in material in which no bulk liquid phase is present.

Thus, a general feature of the behavior being contemplated is that with surface-active, low-solubility impurities present, as normal grain growth occurs, the grain boundaries sweep up impurity. When a critical level of impurity is reached that can trigger a transformation whose function is to make a boundary more mobile than are the rest, AGG is initiated. The condition to sustain AGG depends on maintaining an appropriate range of adsorbate at the moving boundary as impurity is being swept up, by forming precipitates that become entrapped behind the moving boundary; this does not rely on the crystallography of the abnormal grain boundary.

\section{Acknowledgments}

We thank Mrs. M. Sycha for preparation of the TEM specimens, Mr. J. Thomas for assistance operating the STEM, Mrs. S. Kühnemann for assistance using the SEM, and Mr. A. Meyer for ICP-AES analysis of trace element concentrations in the ceramics.

\section{References}

${ }^{1}$ H. Song and R. L. Coble, "Origin and Growth Kinetics of Platelike Abnormal Grains in Liquid-Phase Sintered Alumina," J. Am. Ceram. Soc., 73 [7] 2077-85 (1990).

${ }^{2}$ C. W. Park and D. Y. Yoon, "Effects of $\mathrm{SiO}_{2}, \mathrm{CaO}_{2}$, and $\mathrm{MgO}$ Additions on the Grain Growth of Alumina," J. Am. Ceram. Soc., 83 [10] 2605-609 (2000).

${ }^{3}$ Y. M. Kim, S. H. Hong, and D. Y. Kim, "Anisotropic Abnormal Grain Growth in $\mathrm{TiO}_{2} / \mathrm{SiO}_{2}$-Doped Alumina," J. Am. Ceram. Soc., 83 [11] 2809-12 (2000).

${ }^{4}$ A. Kebbede, J. Parai, and A. H. Carim, "Anisotropic Grain Growth in $\alpha-\mathrm{Al}_{2} \mathrm{O}_{3}$ with $\mathrm{SiO}_{2}$ and $\mathrm{TiO}_{2}$ Additions," J. Am. Ceram. Soc., 83 [11] 2845-51 (2000).

${ }^{5}$ S. H. Hong and D. Y. Kim, "Effect of Liquid Content on the Abnormal Grain Growth of Alumina," J. Am. Ceram. Soc., 84 [7] 1597-600 (2001).

${ }^{6}$ I. J. Bae and S. Baik, "Abnormal Grain Growth of Alumina," J. Am. Ceram. Soc., 80 [5] 1149-56 (1997).

${ }^{7}$ T. W. Sone, J. H. Han, S. H. Hong, and D. Y. Kim, "Effect of Surface Impurities on the Microstructure Development during Sintering of Alumina," J. Am. Ceram. Soc., 84 [6] 1386-88 (2001).

${ }^{8}$ S. I. Bae and S. Baik, "Sintering and Grain Growth of Ultrapure Alumina," J. Mater. Sci., 28, 4197-204 (1993).

${ }^{9}$ R. L. Coble and J. E. Burke, "Sintering in Ceramics"; pp. 197-251 in Progress in Ceramic Science, Vol. 3. Edited by J. E. Burke. Pergamon Press, New York, 1963.

${ }^{10} \mathrm{~W}$. C. Johnson and R. L. Coble, "A Test of the Second Phase and ImpuritySegregation Models for MgO-Enhanced Densification of Sintered Alumina," J. Am. Ceram. Soc., 61 [3-4] 110-14 (1978).

${ }^{11} \mathrm{~S}$. J. Bennison and M. P. Harmer, "A History of the Role of $\mathrm{MgO}$ in the Sintering of $\alpha-\mathrm{Al}_{2} \mathrm{O}_{3}$ "; pp. 13-49 in Ceramic Transactions, Vol. 7, Sintering of Advanced Ceramics. Edited by C. A. Handwerker, J. E. Blendell, and W. A. Kaysser. American Ceramic Society, Columbus, OH, 1990.

${ }^{12}$ K. K. Soni, A. M. Thompson, M. P. Harmer, D. B. Williams, J. M. Chabala, and R. Levi-Setti, "Solute Segregation to Grain-Boundaries in MgO-Doped Alumina," Appl. Phys. Lett., 66 [21] 2795-97 (1995).
${ }^{13}$ K. L. Gavrilov, S. J. Bennison, K. R. Mikeska, and R. Levi-Setti, "Grain Boundary Chemistry of Alumina by High-Resolution Imaging SIMS," Acta Mater., 47 [15] 4031-4039 (1999).

${ }^{14}$ P. Gordon and R. A. Vandermeer, "Grain Boundary Migration"; pp. 205-66 in Recrystallization, Grain Growth and Textures. Edited by H. Margolin. American Society for Metals, Metals Park, OH, 1965.

${ }^{15}$ C. J. Simpson, K. T. Aust, and W. C. Winegard, "4 Stages of Grain Growth," Metall. Trans., 2 [4] 987-91 (1971).

${ }^{16} \mathrm{G}$. Gottstein and L. S. Shvindlerman; Ch. 3 in Grain Boundary Migration in Metals. CRC Press, Boca Raton, FL, 1999.

${ }^{17}$ M. F. Yan, R. M. Cannon, and H. K. Bowen, "Grain Boundary Migration in Ceramics"; pp. 276-307 in Ceramic Microstructures '76. Edited by J. A. Pask and R. A. Fulrath. Westview Press, Boulder, CO, 1977.

${ }^{18}$ (a) A. M. Glaeser, H. K. Bowen, and R. M. Cannon, "Grain Boundary Migration in LiF: I, Mobility Measurements," J. Am. Ceram. Soc., 69 [2] 119-26 (1986). (b) A. M. Glaeser, H. K. Bowen, and R. M. Cannon, "Grain Boundary Migration in LiF: II, Microstructural Characteristics," J. Am. Ceram. Soc., 69 [4] 299-309 (1986).

${ }^{19} \mathrm{I}-\mathrm{W}$. Chen, "Grain Boundary Kinetics in Oxide Ceramics with the Cubic Fluorite Crystal Structure and Its Derivatives," Interface Sci., 8 [2-3] 147-56 (2000).

${ }^{20}$ N. J. Shaw and R. J. Brook, "Structure and Grain Coarsening during Sintering of Alumina," J. Am. Ceram. Soc., 69 [2] 107-10 (1986).

${ }^{21}$ C. A. Handwerker, P. A. Morris, and R. L. Coble, "Effect of Chemical Inhomogeneities on Grain Growth and Microstructure in $\mathrm{Al}_{2} \mathrm{O}_{3}$," J. Am. Ceram. Soc., 72 [1] 130-36 (1989).

${ }^{22}$ S. I. Bae and S. Baik, "Determination of Critical Concentrations of Silica and/or Calcia for Abnormal Grain Growth in Alumina," J. Am. Ceram. Soc., 76 [4] 1065-67 (1993).

${ }^{23}$ I. J. Bae and S. Baik, "Abnormal Grain Growth in Alumina"; pp. 485-90 in Materials Science Forum, Vols. 204-206, Grain Growth in Polycrystalline Materials II. Transtec Publications, Zurich-Uetikon, Switzerland, 1996.

${ }^{24} \mathrm{~J}$. Tartaj and G. L. Messing, "Anisotropic Grain Growth in á-FeO ${ }_{3}$-Doped Alumina," J. Eur. Ceram. Soc., 17 [5] 719-25 (1997).

${ }^{25}$ D. S. Horn and G. L. Messing, "Anisotropic Grain-Growth in TiO-Doped Alumina," Mater. Sci. Eng. A, 195 [1-2] 169-78 (1995).

${ }^{26}$ J. D. Powers and A. M. Glaeser, "Grain Boundary Migration in Ceramics," Interface Sci., 6 [1-2] 23-39 (1998).

${ }^{27}$ J. Rödel and A. M. Glaeser, "Anisotropy of Grain Growth in Alumina," J. Am. Ceram. Soc., 73 [11] 3292-301 (1990).

${ }^{28}$ W. D. Kaplan, H. Müllejans, M. Rühle, J. Rödel, and N. Claussen, "Ca Segregation to Basal Surfaces in $\alpha$-Alumina," J. Am. Ceram. Soc., 78 [10] 2841-44 (1995)

${ }^{29}$ Y. K. Simpson and C. B. Carter, "Faceting Behaviour of Alumina in the Presence of a Glass," J. Am. Ceram. Soc., 73 [8] 2391-98 (1990).

${ }^{30}$ C. A. Bateman, S. J. Bennison, and M. P. Harmer, "Mechanism for the Role of Magnesia in the Sintering of Alumina Containing Small Amounts of a Liquid Phase," J. Am. Ceram. Soc., 72 [7] 1241-44 (1989).

${ }^{31}$ D. A. Litton and S. H. Garofalini, "Molecular Dynamics Simulations of Calcium Aluminosilicate Intergranular Films on (0001) $\mathrm{Al}_{2} \mathrm{O}_{3}$ Facets," J. Am. Ceram. Soc., 83 [9] 2273-81 (2000).

${ }^{32}$ C. W. Park, D. Y. Yoon, J. E. Blendell, and C. A. Handwerker, "Singular Grain Boundaries in Alumina and Their Roughening Transition," submitted to Acta Mater., 2002.

${ }^{33}$ S. B. Lee, N. M. Hwang, D. Y. Yoon, and M. F. Henry, "Grain Boundary Faceting and Abnormal Grain Growth in Nickel," Metall. Mater. Trans. A, 31A [3A] 985-94 (2000).

${ }^{34}$ S. B. Lee, D. Y. Yoon, and M. F. Henry, "Abnormal Grain Growth and Grain Boundary Faceting in a Model Ni-Base Superalloy," Acta Mater., 48 [12] 3071-80 (2000).

${ }^{35}$ C. Bae, J. G. Park, J. H. Kim, and H. Jeon, "Abnormal Grain Growth of Niobium-Doped Strontium Titanate Ceramics," J. Am. Ceram. Soc., 81 [11] 30053009 (1998).

${ }^{36}$ B. K. Lee, S. Y. Chung, and S. J. L. Kang, "Grain Boundary Faceting and Abnormal Grain Growth in $\mathrm{BaTiO}_{3}$," Acta Mater., 48 [7] 1575-80 (2000).

${ }^{37}$ S. B. Lee, W. Sigle, and M. Rühle, "Investigation of Grain Boundaries in Abnormal Grain Growth Structure of $\mathrm{TiO}_{2}$-Excess $\mathrm{BaTiO}_{3}$ by TEM and EELS Analysis," Acta Mater., 50 [8] 2151-62 (2002).

${ }^{38}$ T. H. Huang, M. N. Rahaman, T. I. Mah, and T. A. Parthasarathay, "Anisotropic Grain Growth and Microstructural Evolution of Dense Mullite above $1550^{\circ} \mathrm{C}$," J. Am. Ceram. Soc., 83 [1] 204-10 (2000).

${ }^{39}$ Y. K. Jeong, A. Nakahira, and K. Niihara, "Effects of Additives on Microstructure and Properties of Alumina-Silicon Carbide Nanocomposites," J. Am. Ceram. Soc., 82 [12] 3609-12 (1999).

${ }^{40}$ J. Wang, C. B. Ponton, and P. M. Marquis, "Abnormal Grain Growth in Alumina-Doped Hafnia Ceramics," J. Mater. Sci., 29, 3577-90 (1994).

${ }^{41}$ J. H. Yoo, J. C. Nam, and S. Baik, "Quantitative Evaluation of Glass-Forming Impurities in Alumina: Equivalent Silica Concentration," J. Am. Ceram. Soc., 82 [8] 2235-38 (1999).

${ }^{42}$ M. A. Gülgün, R. Voytovych, I. MacLaren, M. Rühle, and R. M. Cannon, "Cation Segregation in an Oxide Ceramic with Low Solubility: Yttrium Doped

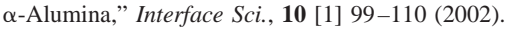

${ }^{43}$ R. Voytovych, I. MacLaren, M. A. Gülgün, R. M. Cannon, and M. Rühle, "The Effect of Yttrium on Densification and Grain Growth in $\alpha$-Alumina," Acta Mater., 50 [13] 3453-63 (2002).

${ }^{44}$ M. A. Gülgün, R. M. Cannon, and M. Rühle, "Variable Microchemistry in a Polycrystalline Alumina with Y, Si, and Ca Impurities," submitted to J. Am. Ceram. Soc., 2002.

${ }^{45}$ (a) F. J. T. Lin, L. C. De Jonghe, M. N. Rahaman, "Microstructure Refinement of Sintered Alumina by a Two-Step Sintering Technique," J. Am. Ceram. Soc., 80 [9] 2269-77 (1997). (b) F. J. T. Lin, L. C. De Jonghe, and M. N. Rahaman, "Initial 
Coarsening and Microstructural Evolution of Fast-Fired and MgO-Doped $\mathrm{AlO}_{3}$," J. Am. Ceram. Soc., 80 [11] 2891-96 (1997).

${ }^{46}$ M. Rühle, C. Springer, L. J. Gaukler, and M. Wilkens, "TEM Studies of Phases in Si-Al-O-N Alloys"; pp. 641-44 in Proceedings of the Fifth International Conference on High-Voltage Electron Microscopy. Edited by T. Imura and H. Hashimoto. Japan Society of Electron Microscopy, Tokyo, Japan, 1977.

${ }^{47}$ O. L. Krivanek, T. M. Shaw, and G. Thomas, "Imaging of Thin Intergranular Phases by High-Resolution Electron Microscopy," J. Appl. Phys., 50, 4223-27 (1979).

${ }^{48}$ D. R. Clarke, "On the Detection of Thin Intergranular Films by Electron Microscopy," Ultramicroscopy., 4, 33-44 (1979).

${ }^{49}$ R. F. Egerton, Electron Energy-Loss Spectroscopy in the Electron Microscope, 2nd ed. Plenum Publishing, New York, 1996.

${ }^{50}$ J. Mayer, U. Eigenthaler, J. M. Plitzko, and F. Dettenwanger, "Quantitative Analysis of Electron Spectroscopic Imaging Series," Micron, 28 [5] 361-70 (1997).

${ }^{51}$ U. Alber, H. Müllejans, and M. Rühle, "Improved Quantification of Grain Boundary Segregation by EDS in a Dedicated STEM," Ultramicroscopy, 69 [2] 105 (1997).

${ }^{52}$ M. K. Cinibulk, H. J. Kleebe, and M. Rühle, "Quantitative Comparison of TEM Techniques for Determining Amorphous Intergranular Film Thickness," J. Am. Ceram. Soc., 76 [2] 426-32 (1993).

${ }^{53}$ I. MacLaren, "Enhanced Visibility of Thin Amorphous Interfacial Films using Fourier Filtering of HRTEM Images," manuscript in preparation, 2002.

${ }^{54}$ R. J. Brook, "Pore-Grain Boundary Interactions and Grain Growth," J. Am. Ceram. Soc., 52 [1] 56-57 (1969).

${ }^{55}$ M. F. Yan, R. M. Cannon, H. K. Bowen, and U. Chowdhry, "Effect of Grain Size Distribution on Sintered Density," Mater. Sci. Eng., 60 [3] 275-81 (1983).

${ }^{56}$ R. Brydson, S. C. Chen, F. L. Riley, S. J. Milne, X. Pan, and M. Rühle, "Microstructure and Chemistry of Intergranular Glassy Films in Liquid-PhaseSintered Alumina," J. Am. Ceram. Soc., 81 [2] 369-79 (1998).
${ }^{57}$ A. M. Thompson, K. K. Soni, H. M. Chan, M. P. Harmer, D. B. Williams, J. M. Chabala, and R. Levi-Setti, "Dopant Distributions in Rare-Earth-Doped Alumina," J. Am. Ceram. Soc., 80 [2] 373-76 (1997).

${ }^{58}$ D. Turnbull, "Theory of Grain Boundary Migration Rates," Trans. AIME, 191 [8] 661-65 (1951).

${ }^{59}$ A. P. Sutton and R. W. Balluffi, Interfaces in Crystalline Materials; Ch. 9. Clarenden Press, Oxford, U.K., 1995.

${ }^{60}$ U. Kolitsch, H. J. Seifert, T. Ludwig, and F. Aldinger, "Phase Equilibria and Crystal Chemistry in the $\mathrm{Y}_{2} \mathrm{O}_{3}-\mathrm{Al}_{2} \mathrm{O}_{3}-\mathrm{SiO}_{2}$ System," J. Mater. Res., 14 [2] 447-55 (1999).

${ }^{61}$ I. A. Bondar and F. Ya. Galakhov, Izv. Akad. Nauk SSSR, Ser. Khim., 7, 1325 (1964).

${ }^{62}$ R. A. L. Drew, S. Hampshire, and K. H. Jack, "Nitrogen Glasses"; pp. 119-32 in Proceedings of the British Ceramic Society, Vol. 31, Special Ceramics 7. Edited by D. E. Taylor and P. Popper. British Ceramic Society, Stoke-on-Trent, U.K., 1981.

${ }^{63} \mathrm{~K}$. Lücke and K. Detert, "A Quantitative Theory of Grain Boundary Motion and Recrystallization in Metals in the Presence of Impurities," Acta Metall., 5 [11] 628-37 (1957)

${ }^{64}$ J. W. Cahn, "Impurity Drag Effect on Grain Boundary Motion," Acta Metall., 10 [9] 789-98 (1962)

${ }^{65}$ K. Lücke and H.-P. Stüwe, "On the Theory of Impurity Controlled Grain Boundary Migration," Acta Metall., 19 [10] 1687-99 (1971).

${ }^{66}$ M. A. Gülgün and M. Rühle, "Yttrium in Polycrystalline $\alpha$-Alumina"; pp. 793-800 in Key Engineering Materials, Vols. 171-174, Creep and Fracture of Engineering Materials and Structures. Edited by T. Sakuma and K. Yagi. Transtec Publications, Zurich-Uetikon, Switzerland, 1999.

${ }^{67}$ M. A. Gülgün, R. Voytovych, E. Bischoff, R. M. Cannon, and M. Rühle, "Microstructural Development in $\alpha-\mathrm{Al}_{2} \mathrm{O}_{3}$ "; pp. $115-25$ in Ceramic Transactions, Vol. 118, Grain Boundary Engineering in Ceramics. American Ceramic Society, Westerville, $\mathrm{OH}, 2000$. 